\title{
Role of Sympathovagal Imbalance in Gestational Hypertension: A Mini-Review
}

\author{
Kuzhanthaivelu Karthiga', Gopal Krushna Pal ${ }^{1, *}$, Subramaniyam Velkumary', Dasari Papa ${ }^{2}$, Nivedita Nanda ${ }^{3}$
}

\section{Kuzhanthaivelu Karthiga', Gopal Krushna Pal',*, Subramaniyam Velkumary', Dasari Papa², Nivedita Nanda ${ }^{3}$}

\section{${ }^{1}$ Department of Physiology, Jawaharlal Institute of Post-graduate Medical Education and Research (JIPMER), Puducherry, INDIA. \\ ${ }^{2}$ Department of Obstetrics and Gynaecology, Jawaharlal Institute of Post-graduate Medical education and Research (JIPMER), Puducherry, INDIA. ${ }^{3}$ Department of Biochemistry, Jawaharlal Institute of Post-graduate Medical Education and Research (JIPMER), Puducherry, INDIA. \\ * Correspondence \\ Dr. Gopal Krushna Pal \\ Senior Professor of Physiology, Department of Physiology, Jawaharlal Institute of Post-graduate Medical Education and Research (JIPMER), Puducherry-605 006, INDIA. \\ Phone: +91-9344291160 \\ Email: drgkpal@gmail.com \\ History \\ - Submission Date: 17-08-2019 \\ - Review completed: 28-10-2019; \\ - Accepted Date: 06-11-2019.}

DOI : 10.5530/ijcep.2019.6.4.30

\section{Copyright}

(C) 2019 Phcog.Net. This is an openaccess article distributed under the terms of the Creative Commons Attribution 4.0 International license.

\begin{abstract}
Hypertension is one of the most common medical problem encountered in about $15 \%$ of pregnancies and it contributes to $12 \%$ of maternal morbidity and mortality especially in developing countries of south-east Asia. The Autonomic Nervous System (ANS) has a prominent role in the cardiovascular system adaptation to pregnancy. However, in gestational hypertension, sympathetic overactivity leads to intense vasoconstriction that results in hypertension. Current evidence suggests that sympathovagal imbalance is highly prevalent in women with Gestational Hypertension (GHT). The sympathovagal imbalance is a major cardiovascular risk in hypertensive disorders including the hypertensive disorders of pregnancy. Thus, sympathovagal imbalance is not only the physiological mechanism for genesis of hypertension in GHT, but also a major contributor to cardiovascular risk in GHT.

Key words: Gestational hypertension, Sympathovagal imbalance, Baroreflex sensitivity, Cardiovascular risks, Autonomic dysregulation.
\end{abstract}

\section{GESTATIONAL HYPERTENSION:}

\section{Definition, Types, Disease Burden}

Hypertension is one of the most common medical problem encountered in about $15 \%$ of pregnancies and it contributes to $12 \%$ of maternal morbidity and mortality especially in developing countries of south-east Asia. ${ }^{[1,2]}$ Gestational hypertension (GHT) is defined as a systolic BP of at least $140 \mathrm{~mm} \mathrm{Hg}$ and/ or a diastolic blood pressure of at least $90 \mathrm{~mm} \mathrm{Hg}$ on at least two occasions at least $6 \mathrm{hr}$ apart after the $20^{\text {th }}$ week of gestation in women known to be normotensive before pregnancy. ${ }^{[3]}$ Hypertensive Disorders of Pregnancy (HDP) complicate 5\% to $10 \%$ of pregnancies and are increasing the prevalence of cardiometabolic diseases in younger women. ${ }^{[4]}$ Normal pregnancy is marked by an initial drop in mean arterial pressure, with an eventual rise in Blood Pressure (BP) to pre-pregnancy levels. ${ }^{[5]}$ The development of HDP involves a number of factors that result in volume and hemodynamic alterations that fail to adapt to the changes accompanying pregnancy.

\section{Classification and Epidemiology of HDP}

The American College of Obstetricians and Gynecologists (ACOG) classifies 4 categories of HDP. ${ }^{[6]}$ In 2017, the American College of Cardiology and American Heart Association (ACC/AHA) issued a clinical practice guideline on hypertension that reclassified the previous category of prehypertension into elevated BP (systolic BP 120-129 mm Hg) and stage 1 hypertension (systolic BP 130-139 mm Hg or diastolic BP $80-89 \mathrm{~mm} \mathrm{Hg}){ }^{[7]}$ The ACOG guidelines do not incorporate the most recent hyper- tension definitions and this is an area in which new evidences are essential. A recent re-examination of the high-risk aspirin trial data during pregnancy reported that the newly identified stage 1 hypertension in pregnancy was associated with increased risk of preeclampsia compared with normotensive women (39\% versus $15 \%$ ) and that randomization to aspirin reduced this risk (24\% versus $39 \%) .{ }^{[8]}$

\section{Prevalence and Disease Risk Burden}

There are well established associations between HDP and the development of maternal Cardiovascular Disease (CVD) later in life. Although the associations between preeclampsia and future CVD have long been known, newer evidence suggests that there are also long-term CVD risks associated with Gestational Hypertension (GHT), although the etiology of GHT is thought to be distinct from that of preeclampsia. Whether preeclampsia and GH result as manifestations of already preexisting CVD risk or whether they contribute to the pathogenesis of later CVD development is unclear.

\section{PATHOPHYSIOLOGY OF GHT}

Uteroplacental insufficiency and a susceptible maternal vascular and metabolic phenotype are the underlying etiology of gestational hypertension. It is well established, however, that the condition is heterogeneous, with multiple pathways leading to vasoconstriction and end-organ ischemia. Preeclampsia aggregates in families ${ }^{[9]}$ and new evidence suggests that fetal genetic variants near FLT1 (fms-related tyrosine kinase 
1), a gene involved in angiogenesis, may contribute to risk. ${ }^{[10,11]}$ Precise causes of preeclampsia are still unknown, but the factors that contributes for preeclampsia includes impaired angiogenesis, ${ }^{[12]}$ systemic endothelial dysfunction, ${ }^{[13]}$ and decreased vascular compliance resulting in impaired accommodation of the volume expansion required for healthy gestation. ${ }^{[14]}$ Importantly, preeclampsia involves multisystem dysfunction. There is evidence of structural and functional cardiac impairments in women during pregnancies complicated by gestational hypertension. ${ }^{[15-17]}$ Cardiometabolic risk factors are also elevated during these pregnancies. ${ }^{[18]}$

It is unclear if GHT has a different etiology from preeclampsia or whether is an early stage of a shared phenomenon. GHT and preeclampsia have similar risk factors, such as obesity, parity and history of preeclampsia in previous pregnancies. There are race disparities in the risk factors and prevalence of both GHT and preeclampsia, with black women carrying a higher burden of disease. ${ }^{[19]}$ The risk of adverse newborn outcomes is higher with preeclampsia when compared to GHT. In one study, the risk of preterm delivery was found in to be $7.2 \%$ in normotensive women, $12.5 \%$ in women with GHT and $39.2 \%$ in those with preeclampsia. ${ }^{[20]}$ Studies report that the level of inflammatory markers may be distinct in women with GHT compared with preeclampsia, with the possibility that women with GHT can compensate more successfully. ${ }^{[21]}$ In contrast, preeclampsia is more often associated with placental disease characterized by impaired markers of angiogenesis. ${ }^{[22]}$ Progression to chronic hypertension after delivery may help further elucidate whether GHT and preeclampsia have different etiologies. Specifically, $42 \%$ of women with preeclampsia and 39\% of women with GHT progress to hypertension after mean follow-up of 2.5 years compared with rates as low as $1 \%$ among the women with normotensive pregnancies. ${ }^{[23,24]}$

\section{SYMPATHOVAGAL IMBALANCE}

\section{Concept and its Role in Hypertension}

The major pathophysiology of primary hypertension (HTN) is vasoconstriction induced by increased sympathetic tone. ${ }^{[25]} \mathrm{Pal}$ et al. have reported that there is contribution of vagal withdrawal in addition to the sympathetic over activity in the genesis of HTN ${ }^{[26]}$ Recently, sympathovagal imbalance (the autonomic dysfunction due to inequality between sympathetic and parasympathetic activities) has emerged as the main physiological support to explain the role of autonomic neuro- physiological mechanisms in various clinical disorders. ${ }^{[27-32]}$

Emotional responses of the body and responses to the environment occur without conscious effort of the individual. These responses are called autonomic responses and are executed through the autonomic part of the nervous system, known as the Autonomic Nervous System (ANS). ${ }^{[33]}$ Through its innervation to all visceral organs, the ANS controls all major functions of the body, such as circulation, respiration, digestion, excretion, reproduction, immunity and metabolism. The ANS executes its functions through its two major subdivisions: the sympathetic and the parasympathetic systems. Broadly, the sympathetic system is involved in energy mobilization and utilization and the parasympathetic system in energy restoration and storage. ${ }^{[33]}$ Although these divisions of the ANS are physiologically opposite, they are reciprocal to each other in their outflow and functions. Normally, the body tries to maintain a balance between the storage and utilization of energy by balancing the parasympathetic and sympathetic activities. In a healthy individual, sympathetic and parasympathetic (vagal) systems are in dynamic balance, known as sympathovagal balance, which contributes to effective internal homeostasis. ${ }^{[34]}$

As blood vessels of systemic vasculature are stimulated exclusively by sympathetic vasoconstrictor fibers, sympathetic overactivity was suggested to be the primary pathophysiological mechanism for essential HTN. ${ }^{[35-39]}$ Earlier it was documented that the initial phase of HTN is characterized by increased cardiac output and normal peripheral resistance, whereas in established HTN, cardiac output remains normal with increased peripheral vascular resistance. ${ }^{[40]}$ It was observed that in patients with chronic HTN, vascular resistance remains elevated even after a complete blockade of the ANS suggesting that vascular tone in established HTN is not dependent on autonomic tone for its maintenance. ${ }^{[41,42]}$ Also, it was observed that the level of plasma norepinephrine, the index of sympathetic activity that remains high in the early phase of HTN, normalizes in established HTN. ${ }^{[43-45]}$ These observations indicate the transformation from hyperkinetic circulation in early borderline HTN to a high vascular resistance in established HTN with the normalization of markers of enhanced sympathetic tone. ${ }^{[40]}$ However, the reports of recent studies reveals that the sympathetic drive remains elevated in established HTN. ${ }^{[35-39]}$ Thus, it appears that a decline in the hemodynamic response to sympathetic drive, not the decrease in sympathetic tone itself and also down-regulation of cardiac $\beta$-adrenergic receptors in response to sustained elevation in sympathetic tone normalize cardiac output in established HTN. ${ }^{[40]}$ The progressive increase in vascular resistance in established HTN is explained by Folkow's theory, which explains that adaptive vascular hypertrophy of the resistance blood vessels with progressive thickening of smooth muscle of the tunica media results in an increase in the wall-lumen ratio in chronically elevated $\mathrm{BP}{ }^{[46]}$ The structural changes in the vessel wall in chronic HTN render blood vessels hyper-responsive to circulating endogenous vasoconstrictors, which amplifies the already existing increased vascular resistance. ${ }^{[47-49]}$ There are also reports that increase in sympathetic tone causes thickening of the vessel wall, ${ }^{[0,51]}$ and increases the vascular reactivity. ${ }^{[52,53]}$ Thus, increased vascular resistance in HTN is a neural-vascular-humoral mechanism, in which autonomic modulation plays an important role in determining the vasomotor tone.

\section{SYMPATHOVAGAL IMBALANCE IN GHT}

The Autonomic Nervous System (ANS) has a prominent role in the cardiovascular system adaptation to pregnancy. ${ }^{[54]}$ Normal pregnancy is associated with a decrease of parasympathetic and increase of sympathetic activity at rest and upon cardiovascular reflexes stimulation which returns to baseline after delivery. These changes maintain optimal uteroplacental blood flow. ${ }^{[55,56]}$ The factors that largely contribute to the development of hypertension are decreased size of the vascular compartment (vasoconstriction) and increase volume of the compartment (increased blood volume). ${ }^{[57]}$ However, in this dysfunction, hypertension develops inspite of low blood volume, which clearly indicates that the primary contributor to GHT is increased vasoconstriction induced by sympathetic over-reactivity. ${ }^{[58]}$ Recent reports from our laboratory confirmed that there is increase in sympathetic tone by spectral HRV analysis in the first trimester of pregnancy in women with high risks for GHT predicts the development of GHT in these women that clinically manifests in third trimester of pregnancy. ${ }^{[59,60]}$

\section{Assessment of Autonomic Functions in GHT}

Heart Rate Variability (HRV) is a widely used non-invasive clinical tool that provides a valuable measure of sympathetic and parasympathetic function. ${ }^{[61]}$ The derived HRV indices are determined in two domains, time domain and frequency domain. The majority of HRV parameters indicate parasympathetic influences, ${ }^{[62]}$ while only low frequency (LF) power is influenced by the sympathetic nervous system. ${ }^{[63]}$ LF-HF ratio, the index of sympathovagal homeostasis represents the balance between sympathetic and parasympathetic activities of the individual at any given time in resting supine conditions. Lesser values of this ratio indicate there is more parasympathetic activity and greater values indicate sympathetic overactivity. ${ }^{[64]}$ 
The autonomic nervous system activity can also be evaluated by measuring the sensitivity of baroreceptors embedded in the carotid sinus and aortic arch walls. Baroreceptor reflex serves as "buffering" mechanism to control sudden fluctuations in blood pressure.

Another tool that provides an estimate of sympathetic activity is measuring plasma and urinary catecholamines in addition to other blood markers e.g., neuropeptide $\mathrm{Y}^{\left[{ }^{[65]}\right.}$ All biomarkers of sympathetic activity has the limitation of being affected by numerous confounding factors that can make interpretation difficult. ${ }^{[66]}$

\section{CONCLUSION}

Pregnancy Induced Hypertension (PIH) is currently referred to as Gestational Hypertension (GHT). PIH is a state of volume contraction (decreased ECF volume and blood volume). Generally, in a state of volume contraction blood pressure decreases, as ECF volume is a major contributor to cardiac output and therefore to systolic blood pressure. However, in PIH (GHT), sympathetic overactivity leads to intense vasoconstriction that results in hypertension. Moreover, the recent reports from our laboratory have demonstrated in addition to sympathetic overactivity, there is considerable vagal withdrawal especially in the later part of pregnancy. This results in sympathovagal imbalance (sympathetic overactivity vagal withdrawal). The sympathovagal imbalance is a major cardiovascular risk thus sympathovagal imbalance is not only the physiological mechanism for genesis of hypertension in GHT, but also a major contributor to cardiovascular risk in GHT. Therefore, lifestyle modifications especially practice of yoga may be encouraged to pregnant women with risk factors of pregnancy to ensure sympathovagal homeostasis, prevent the genesis of hypertension in pregnancy, as there are reports of attainment of sympathovagal balance by practice of yoga such as slow pranayamas. ${ }^{[67]}$

\section{CONFLICT OF INTEREST}

The authors declare no conflict of interest.

\section{ABBREVIATIONS}

ANS: Autonomic Nervous System; GHT: Gestational Hypertension; HDP: Hypertensive Disorders of Pregnancy; BP: Blood Pressure; ACOG: American College of Obstetricians and Gynecologists; ACC: American College of Cardiology; AHA: American Heart Association; CVD: Cardiovascular Disease; FLT1: fms-related tyrosine kinase 1; HRV: Heart Rate Variability; PIH: Pregnancy Induced Hypertension; LF: Low Frequency.

\section{REFERENCES}

1. James PR, Nelson-Piercy C. Management of hypertension before, during and after pregnancy. Heart. 2004;90(12):1499-504.

2. Pal P, Pal GK, Sridhar M, Subha M, Syed H, Adithan C. Association of sympathovagal imbalance with arterial stiffness indices in women with risk factors for pregnancy-induced hypertension in first and third trimesters of gestation. Int $J$ Clin Exp Physiol. 2014;1 (2):113-9.

3. Sibai B. Diagnosis and Management of Gestational Hypertension and Preeclampsia. Obstet Gynecol. 2003;102(1):181-92.

4. Hutcheon JA, Lisonkova S, Joseph KS. Epidemiology of pre-eclampsia and the other hypertensive disorders of pregnancy. Best Pract Res Clin Obstet Gynaecol. 2011;25(4):391-403.

5. Mustafa R, Ahmed S, Gupta A, Venuto RC. A comprehensive review of hypertension in pregnancy. J Pregnancy. 2012;2012:105918.

6. American College of Obstetricians and Gynecologists. Hypertension in pregnancy. Report of the American College of Obstetricians and Gynecologists' Task Force on Hypertension in Pregnancy. Obstet Gynecol. 2013;122(5):1122-31.

7. Whelton PK, Carey RM, Aronow WS, Casey DEJ, Collins KJ, Dennison HC, et al. 2017ACC/AHA/AAPA guideline for the prevention, detection, evaluation and management of high blood pressure in adults: Executive summary: A report of the American College of Cardiology/ American Heart Association Task Force on Clinical Practice Guidelines. Hypertension. 2018;71(6):1269-324.

8. Hauspurg A, Sutton E, Catov J, Caritis S. Applying the new ACC/AHA Aspirin effect on adverse pregnancy outcomes associated with Stage 1 hypertension in a high-risk cohort. Hypertension. 2018;72(1):202-7.

9. Sven C, Marie R, Yudi P, Paul L. Maternal and fetal genetic factors account for most of familial aggregation of preeclampsia: A population-based Swedish cohort study. Am J Med Genet A. 2004;130A(4):365-71.

10. McGinnis R, Steinthorsdottir V, Williams NO, Thorleifsson G, Shooter S, Hjartardottir S, et al. Variants in the fetal genome near FLT1 are associated with risk of preeclampsia. Nat Genet. 2017;49(8):1255.

11. Gray KJ, Saxena R, Karumanchi SA. Genetic predisposition to preeclampsia is conferred by fetal DNA variants near FLT1, a gene involved in the regulation of angiogenesis. Am J Obstet Gynecol. 2018;218(2):211-8.

12. Karumanchi SA. Angiogenic factors in preeclampsia: From diagnosis to therapy. Hypertension. 2016;67(6):1072-9.

13. Roberts JM. Endothelial dysfunction in preeclampsia. Semin Reprod Endocrinol. 1998;16(1):5-15

14. Hausvater A, Giannone T, Sandoval YH, Doonan RJ, Antonopoulos CN, Matsoukis IL, et al. The association between preeclampsia and arterial stiffness. J Hypertens. 2012;30(1):17-33.

15. Shivananjiah $C$, Nayak $A$, Swarup A. Echo changes in hypertensive disorder of pregnancy. J Cardiovasc Echogr. 2016;26(3):94-6.

16. Melchiorre K, Sutherland GR, Baltabaeva A, Liberati M, Thilaganathan B. Maternal cardiac dysfunction and remodeling in women with preeclampsia at term. Hypertension. 2011;57(1):85-93.

17. Melchiorre K, Sutherland GR, Watt-Coote I, Liberati M, Thilaganathan B. Severe myocardial impairment and chamber dysfunction in preterm preeclampsia. Hypertens Pregnancy. 2012;31(4):454-71.

18. Borghi C, Esposti DD, Immordino V, Cassani A, Boschi S, Bovicelli L, et al. Relationship of systemic hemodynamics, left ventricular structure and function and plasma natriuretic peptide concentrations during pregnancy complicated by preeclampsia. Am J Obstet Gynecol. 2000;183(1):140-7.

19. Breathett K, Muhlestein D, Foraker R, Gulati M. Differences in preeclampsia rates between African American and Caucasian women: Trends from the National Hospital Discharge Survey. J Womens Health. 2014;23(11):886-93.

20. Shen M, Smith GN, Rodger M, White RR, Walker MC, Wen SW. Comparison of risk factors and outcomes of gestational hypertension and pre-eclampsia. PLoS One. 2017;12(4):e0175914.

21. Tangeras LH, Austdal M, Skrastad RB, Salvesen KA, Austgulen R, Bathen TF et al. Distinct first trimester cytokine profiles for gestational hypertension and preeclampsia. Arterioscler Thromb Vasc Biol. 2015;35(11):2478-85.

22. Levine RJ, Maynard SE, Qian C, Lim KH, England LJ, Yu KF, et al. Circulating angiogenic factors and the risk of preeclampsia. N Engl J Med. 2004;350(7):672-83

23. Veerbeek JH, Hermes W, Breimer AY, Rijn BBV, Koenen SV, Mol BW, et al. Cardiovascular disease risk factors after earlyonset preeclampsia, lateonset preeclampsia and pregnancy-induced hypertension. Hypertension. 2015;65(3):600-6.

24. Hermes W, Franx A, Pampus MGV, Bloemenkamp KW, Bots ML, DerPost JAV, et al. Cardiovascular risk factors in women who had hypertensive disorders late in pregnancy: A cohort study. Am J Obstet Gynecol. 2013;208(6):474.e1.

25. Kaplan NM, Victor RG. Primary hypertension - pathogenesis, natural history and evaluation. In: Kaplan's Clinical Hypertension. 10 $0^{\text {th }}$ Ed. USA: Lippincott Williams and Wilkins Publications. 2010;42-140.

26. Pal GK, Adithan C, Amudharaj D, Dutta TK, Pal P, Nandan PG, et al. Assessment of sympathovagal imbalance by spectral analysis of heart rate variability in prehypertensive and hypertensive patients in Indian population. Clin Exp Hypertens. 2011;33(7):478-83.

27. Pal GK, Shyma P, Habeebullah S, Shyjus $P, P a l$ P, Nanda N. Association of albuminglobulin ratio with sympathovagal imbalance in pregnancy-induced hypertension. Indian J Physiol Pharmacol. 2011;55(2):128-38.

28. Pal GK, Shyma P, Habeebullah S, Pal P, Nanda N, Shyjus P. Vagal withdrawal and sympathetic overactivity contribute to the genesis of early-onset pregnancyinduced hypertension. Int J Hypertens. 2011;3:614-7.

29. Karthik S, Pal GK, Nanda N, Hamide A, Bobby Z, Amudharaj D, et al. Sympathovagal imbalance in thyroid dysfunctions in females: correlation with thyroid profile, heart rate and blood pressure. Indian J Physiol Pharmacol. 2009;53(3):243-52.

30. Shiina K, Tomiyama H, Takata Y, Yoshida M, Kato K, Saruhara H, et al. Effects of CPAP therapy on the sympathovagal balance and arterial stiffness in obstructive sleep apnea. Respir Med. 2010;104(6):911-6.

31. Heemstra KA, Burggraaf J, DerKlaauw AAV, Romijn JA, Smit JW, Corssmit EP Short-term overt hypothyroidism induces sympathovagal imbalance in thyroidectomized differentiated thyroid carcinoma patients. Clin Endocrinol. 2010;72(3):417-21

32. Resmini E, Casu M, Patrone V, Murialdo G, Bianchi F, Giusti M, et al. Sympathovagal imbalance in acromegalic patients. J Clin Endocrinol Metab. 2006;91(1):115-20.

33. Pal GK. Sympathetic and parasympathetic systems. In: Textbook of Medical Physiology. Ahuja Publications, New Delhi, India. 2010;209-16.

34. Pal GK. Role of sympathovagal balance in achieving effective homeostasis 
Biomedicine. 2008;28(2):67-8.

35. Gabor A, Leenen FH. Central neuromodulatory pathways regulating sympathetic activity in hypertension. J Appl Physiol. 2012;113(8):1294-303.

36. Hogarth AJ, Graham LN, Corrigan JH, Deuchars J, Mary DA, Greenwood JP Sympathetic nerve hyperactivity and its effect in postmenopausal women. $J$ Hypertens. 2011;29(11):2167-75.

37. Benjelloun H, Aboudrar S, Jroundi I, Benjelloun-Bennani H, Coghlan L, Benomar M. Sympathetic response in primary hypertension. Ann Cardiol Angeiol. 2009;58(3):139-43.

38. Hogarth AJ, Burns J, Mackintosh AF, Mary DA. Sympathetic nerve hyperactivity of essential hypertension is lower in postmenopausal women than men. $J$ Hum Hypertens. 2008;22(8):544-9.

39. Hogarth AJ, Mackintosh AF, Mary DA. The effect of gender on the sympathetic nerve hyperactivity of essential hypertension. J Hum Hypertens. 2007;21(3):239-45.

40. Amerena J, Julius S. Role of the autonomic nervous system in hypertension. Hypertens Res. 1995;18:99-110.

41. Julius $S$, Krause L, Schork $N$, et al. Hyperkinetic borderline hypertension in Tecumseh, Michigan. J Hypertens. 1991;9(1):77-84.

42. Pickering GW. The peripheral resistance in persistent arterial hypertension. Clin Sci. 1936;2:209.

43. Kawano Y, Fukiyama K, Takeya T, Abe I, Omae T. Elevated plasma catecholamines without alteration in cardiovascular responsiveness in young men with borderline hypertension. Am Heart J. 1982;104(6):1351-6.

44. AoiW, Kuramochi M, Hashiba K. Neurohumoral factors in borderline hypertension. Jpn Circ J. 1983;47(2):258-67.

45. Kawano Y, Fukiyama K, Takeya Y, Abe I, Kawasaki T, Omae T. Augmented sympathetic nervous function in young subjects with borderline hypertension. Jpn Circ J. 1982;46(5):483-5.

46. Folkow B. Physiological aspects of primary hypertension. Physiol Rev. 1982;62(2):347-503.

47. Conway J. A vascular abnormality in hypertension: A study of blood flow in the forearm. Circulation. 1963;27(4):520-9.

48. Sivertsson R. The hemodynamic importance of structural vascular changes in essential hypertension. Acta Physiol Scand. 1970;79:3-56.

49. Egan B, Panis R, Hinderliter A, Schork N, Julius S. Mechanism of increased a-adrenergic vasoconstriction in human essential hypertension. J Clin Invest. 1987;80(3):812-7.

50. Dinenno FA, Jones PP, Seals DR, Tanaka H. Age-associated arterial wal thickening is related to elevations in sympathetic activity in healthy humans. Am J Physiol Heart Circ Physiol. 2000;278(4):H1205-10.

51. Joannides R, Richard V, Moore N, Godin M, Thuillez C. Influence of sympathetic tone on mechanical properties of muscular arteries in humans. Am J Physiol. 1995;268(2 Pt 2):H794-801.

52. Mazzone SB, Lim LH, Wagner EM, Mori N, Canning BJ. Sympathetic nerve- dependent regulation of mucosal vascular tone modifies airway smooth muscle reactivity. J Appl Physiol. 2010;109(5):1292-300.

53. Xu H, Fink GD, Galligan JJ. Increased sympathetic venoconstriction and reactivity to norepinephrine in mesenteric veins in anesthetized DOCA-salt hypertensive rats. Am J Physiol Heart Circ Physiol. 2007;293(1):H160-8.

54. Karumanchi SA, Granger JP. Preeclampsia and pregnancy related hypertensive disorders. Hypertension. 2016;67(2):238-42.

55. Heiskanen N, Saarelainen H, Valtonen P, Lyyra-Laitinen T, Laitinen T, Vanninen $E_{\text {, }}$ et al. Blood pressure and heart rate variability analysis of orthostatic challenge in normal human pregnancies. Clin Physiol Funct Imag. 2008;28(6):384-90.

56. Ekholm EM, Piha SJ, Erkkola RU, Antila KJ. Autonomic cardiovascular reflexes in pregnancy: A longitudinal study. Clin Autonom Res. 1994:4(4):161-5.

57. Ganong WF. Cardiovascular regulatory mechanisms: Review of Medical Physiology. 23 $3^{\text {rd }}$ ed. New Delhi: Tata McGraw Hill Education Private Limited. 2010;555-68.

58. Visser W, Wallenburg HCS. Central hemodynamic observations in untreated preeclamptic patients. Hypertension. 1991;17(6):1072-7.

59. Pal GK, Shyma P, Habeebullah S, Shyjus P, Pal P. Spectral analysis of heart rate variability for early prediction of pregnancy-induced hypertension. Clin Exp Hypertens. 2009:31(4):330-41.

60. Shyma P, Pal GK, Habeebullah S, Shyjus P and Pal P. Decreased total power of HRV with increased LF power in early part of pregnancy predicts development $\mathrm{PIH}$ in Indian population. Biomedicine. 2008;28(2):104-7.

61. Camm AJM, Malik JT, Bigger G, Breithardt S, Cerutti RJ, Cohen P, et al. Heart rate variability: Standards of measurement, physiological interpretation and clinical use. Task force of the European society of cardiology and the North American society of pacing and electrophysiology. Circulation. 1996;93(5):1043-65.

62. Kingwell BA, Thompson JM, Kaye DM, McPherson GA, Jennings GL, Esler MD. Heart rate spectral analysis, cardiac norepinephrine spillover and muscle sympathetic nerve activity during human sympathetic nervous activation and failure. Circulation. 1994;90(1):234-40

63. Shaffer F, Ginsberg JP. An overview of heart rate variability metrics and norms. Front Public Health. 2017;5:258.

64. Malliani A. Heart rate variability: from bench to bedside. Eur J Intern Med. 2005;16(1):12-20

65. Morris MJ, Russell AE, Kapoor V, Cain MD, Elliott JM, West MJ, et al. Increases in plasma neuropeptide y concentrations during sympathetic activation in man J Auton Nerv Syst. 1986;17(2):143-9.

66. Freeman R. Assessment of cardiovascular autonomic function. Clin Neurophysiol. 2006;117(4):716-30

67. Pal GK, Agarwal A, Karthik S, Pal P, Nanda N. Slow yogic breathing through right and left nostril influences sympathovagal balance, heart rate variability and cardiovascular risks in young adults. N Am J Med Sci. 2014;6(3):145.

Cite this article: Karthiga K, Pal GK, Velkumary S, Papa D, Nanda N. Role of Sympathovagal Imbalance in Gestational Hypertension: A Mini-Review. Int J Clin Exp Physiol. 2019;6(4):107-10. 